\title{
New materialist social inquiry: designs, methods and the research-assemblage
}

\section{Nick J. Fox \& Pam Alldred}

To cite this article: Nick J. Fox \& Pam Alldred (2015) New materialist social inquiry: designs, methods and the research-assemblage, International Journal of Social Research Methodology, 18:4, 399-414, DOI: 10.1080/13645579.2014.921458

To link to this article: https://doi.org/10.1080/13645579.2014.921458

$$
\begin{aligned}
& \text { (c) } 2014 \text { The Author(s). Published by } \\
& \text { Routledge }
\end{aligned}
$$

\footnotetext{
Published online: 06 Jun 2014.
}

Submit your article to this journal $₫$

ЏII Article views: 16726

Q View related articles

View Crossmark data \lceil

Citing articles: 138 View citing articles $๘$ 


\title{
New materialist social inquiry: designs, methods and the research-assemblage
}

Nick J. Fox ${ }^{\mathrm{a} *}$ and Pam Alldred ${ }^{\mathrm{b}}$

${ }^{a}$ ScHARR, University of Sheffield, 30 Regent St, Sheffield S1 4DA, UK; ${ }^{b}$ Division of Social Work, Centre for Youth Work Studies, Brunel University, Uxbridge UB8 3PH, UK

(Received 22 October 2013; accepted 2 May 2014)

\begin{abstract}
This paper discusses issues of research design and methods in new materialist social inquiry, an approach that is attracting increasing interest across the social sciences as an alternative to either realist or constructionist ontologies. New materialism de-privileges human agency, focusing instead upon how assemblages of the animate and inanimate together produce the world, with fundamental implications for social inquiry methodology and methods. Key to our exploration is the materialist notion of a 'research-assemblage' comprising researcher, data, methods and contexts. We use this understanding first to explore the micropolitics of the research process, and then - along with a review of 30 recent empirical studies - to establish a framework for materialist social inquiry methodology and methods. We discuss the epistemological consequences of adopting a materialist ontology.
\end{abstract}

Keywords: assemblage; Deleuze and Guattari; methodology; new materialism; ontology; research-assemblage; social inquiry

\section{Introduction}

'New' (or 'neo') materialism has emerged over the past 20 years as an approach concerned fundamentally with the material workings of power, but focused firmly upon social production rather than social construction (Coole \& Frost, 2010, p. 7). Applied to empirical research, it radically extends traditional materialist analysis beyond traditional concerns with structural and 'macro' level social phenomena (van der Tuin \& Dolphijn, 2010, p. 159), addressing issues of how desires, feelings and meanings also contribute to social production (Braidotti, 2000, p. 159; DeLanda, 2006 , p. 5). New materialist ontology breaks through 'the mind-matter and culturenature divides of transcendental humanist thought' (van der Tuin \& Dolphijn, 2010, p. 155), and is consequently also transversal to a range of social theory dualisms such as structure/agency, reason/emotion, human/non-human, animate/inanimate and inside/outside. It supplies a conception of agency not tied to human action, shifting the focus for social inquiry from an approach predicated upon humans and their bodies, examining instead how relational networks or assemblages of animate and inanimate affect and are affected (DeLanda, 2006, p. 4; Mulcahy, 2012, p. 10; Youdell \& Armstrong, 2011, p. 145).

*Corresponding author. Email: n.j.fox@sheffield.ac.uk 
These moves pose fundamental questions about how research should be conducted within a new materialist paradigm, and what kinds of data should be collected and analysed. This paper addresses the methodological challenges facing those who wish to apply new materialist ontology to social research. Our point of entry is by considering research as assemblage, a key concept in the materialist ontology that we discuss in the first part of the paper. The research-assemblage (Fox \& Alldred, 2013; Coleman \& Ringrose, 2013, p. 17; Masny, 2013, p. 340) comprises the bodies, things and abstractions that get caught up in social inquiry, including the events that are studied, the tools, models and precepts of research, and the researchers. In conjunction with a review of 30 empirical studies using new materialist ontology, this analysis suggests principles for new materialist research designs and methods.

\section{New materialism and the ontology of the social}

There has been a significant materialist thread throughout the history of empirical social inquiry, for instance, in Marxist and structuralist sociology, which emphasised the contribution to the social world of forces such as the economic system, industrialisation, bureaucracy and governance (Giddens, 1981, pp. 53-55), and in structuralist anthropology (Levi-Strauss, 1986, p. 10). These perspectives were frequently criticised as determinist, leading to a humanistic reaction that sought to more fully account for the part that human beings play in producing and reproducing reality (Berger \& Luckmann, 1971, p. 208; Giddens, 1987, p. 215), although this humanist move has in turn kindled doubts over the assumptions underpinning anthropocentric social inquiry (Tamboukou, 2003, p. 211), and the culture/nature dualism it evokes (Barad, 1997; Clough, 2003; Thacker, 2005).

The 'new' materialisms that have emerged in reaction to humanist social science have drawn together bizarrely disparate strands, including actor-network theory, artificial intelligence, biophilosophy, evolutionary theory, feminism, neuroscience, posthumanism, queer theory, quantum physics and Spinozist monism (Ansell Pearson, 1999; Barad, 1997; Braidotti, 2006, 2013; Clough, 2008; Coole \& Frost, 2010; Grosz, 1994; Haraway, 1997; Latour, 2005; Massumi, 1996; Thacker, 2005). These threads have in common that this is not a return to an earlier reductionist materialism that focused only upon macro structures and super-structures, but a project that

foregrounds an appreciation of just what it means to exist as a material individual with biological needs yet inhabiting a world of natural and artificial objects, well-honed micro-powers of governmentality, but no less compelling effects of international economic structures. (Coole \& Frost, 2010, p. 27)

As Braidotti (2013, p. 3) notes, the eclecticism in new materialism dissolves boundaries between the natural and the cultural, mind and matter, while for Coole and Frost (2010, pp. 27-28) materiality is plural, open, complex, uneven and contingent: new materialist ontologies 'understand materiality in a relational, emergent sense' (ibid., p. 29), with a focus that extends from globalisation to issues of identity. Barad's (1997, p. 181) 'agential realism' similarly dissolves the distinction between nature and culture, rejecting an opposition found in both realist and idealist ontology when she states that 'constructedness does not deny materiality'. Matter is not inert, nor simply the background for human activity, but 'is conceptualised as agentic', with multiple non-human as well as human sources of agency with capacities to affect (Taylor \& Ivinson, 2013, p. 666). 
In this paper, we have chosen to focus on DeleuzoGuattarian ontology, ${ }^{1}$ because of its empirical focus on processes and interactions (Deleuze \& Guattari, 1984, p. 3), its nomadic politics and ethics of becoming rather than being (Braidotti, 2006, p. 14; Conley, 1990), and its methodological capacity to move beyond structure/ agency and culture/nature dualisms (DeLanda, 2006; van der Tuin \& Dolphijn, 2010 , p. 154). These features have given it a significant role in the emergence of new materialism (henceforth in this paper: 'materialism'), with many scholars and most papers in our review of materialist research studies explicitly referencing DeleuzoGuattarian concepts, ontology or ethico-political orientation.

A few paragraphs are needed to summarise this ontology. Firstly, it shifts from conceptions of objects and bodies as occupying distinct and delimited spaces, and instead sees human bodies and all other material, social and abstract entities as relational, having no ontological status or integrity other than that produced through their relationship to other similarly contingent and ephemeral bodies, things and ideas (Deleuze, 1988, p. 123; Deleuze \& Guattari, 1988, p. 261). Assemblages (Deleuze \& Guattari, 1988, p. 88) of relations develop in unpredictable ways around actions and events, 'in a kind of chaotic network of habitual and non-habitual connections, always in flux, always reassembling in different ways' (Potts, 2004, p. 19), and importantly, operate as 'machines' (Deleuze \& Guattari, 1988, p. 4; Guattari, 1995a, p. 35) that do something, produce something. Assemblages develop at subpersonal, interactional or macro social levels (DeLanda, 2006, p. 5), and have an existence independent of human bodies (Ansell Pearson, 1999, pp. 157-159; ibid., p. 40).

The second move is to replace the conventional conception of human agency with the Spinozist notion of affect (Deleuze, 1988, p. 101), meaning simply the capacity to affect or be affected. In an assemblage, there is no 'subject' and no 'object', and no single element possesses agency (Anderson, 2010, p. 736). Rather, an affect is a 'becoming' (Deleuze \& Guattari, 1988, p. 256) that represents a change of state or capacities of an entity (Massumi, 1988, p. xvi): this change may be physical, psychological, emotional or social. Affects produce further affective capacities within assemblages (Deleuze \& Guattari, 1988, p. 400); and because one affect can produce more than one capacity, social production is not linear, but 'rhizomic' (ibid., p. 7), a branching, reversing, coalescing and rupturing flow. Thus, for example, a sexual desire is an affect that may have multiple an unanticipated effects on bodies, resources, interactions and even social institutions such as monogamy.

Finally, assemblages can be seen as 'territories' (Guattari, 1995a, p. 28), produced and disputed by the affects between relations. Affective flows within assemblages render them constantly in flux, with territorialising flows stabilising an assemblage, while others de-stabilise or de-territorialise it (Deleuze \& Guattari, 1988, pp. 88-89), sometimes leading to dis-assembly and 'lines of flight' by constituent elements (Ansell Pearson, 1999, p. 172). These territorialisations and deterritorialisations are the means by which lives, societies and history unfold, 'in a world which is constantly becoming' (Thrift, 2004, p. 61).

\section{Materialism and social inquiry}

We turn now to the implications of this materialist ontology of assemblage, affect and territorialisation for social inquiry, and the methodological and ethico-political challenges it produces. 
First, with the unit of analysis firmly shifted from human agents to the assemblage, the concern is no longer with what bodies or things or social institutions are, but with the capacities for action, interaction, feeling and desire produced in bodies or groups of bodies by affective flows (Deleuze, 1988, p. 127). Social inquiry must remake its vocabulary to reflect this shift from agency to affect, and adapt its methods to attend to affective flows and the capacities they produce. The tools of interpretive research such as interviews or diary and narrative accounts, which conventionally attend to human actions, experiences and reflections, must be turned decisively to efforts to disclose the relations within assemblages, and the kinds of affective flows that occur between these relations (Fox \& Ward, 2008b, p. 1013; Juelskjaer, 2013, p. 759; Renold \& Mellor, 2013, p. 26).

Second, the processual character of assemblages undermines any conception of a determining social structure that shapes bodies or subjectivities. Both the exercise of power or control and the capacity to resist such power and control must be explored as socially and spatiotemporally specific occurrences within continual and continuous flows of affect in assemblages (Buchanan, 2008, pp. 16-17). An important distinction may be made in terms of what we here call 'aggregative' and 'singular' affects, ${ }^{2}$ and the capacities they produce in bodies and assemblages. Aggregative affects (such as a sexual code of conduct) assemble and systematise bodies and things into collectivities, smooth out differences and divergences to generate classificatory concepts such as gender and race; and underpin broad social and cultural formations such as patriarchy, nationalism and heteronormativity (Clough, 2008, p. 2; DeLanda 2006, p. 72; Deleuze \& Guattari, 1984, pp. 286-288). By contrast, singular affects (for instance, a caress during a sexual encounter, or a kind word from a stranger) possess no aggregative capacity, and on occasions may de-territorialise and fragment assemblages, producing 'lines of flight' away from stable or organised formations or classifications.

Third, the dissolution of both agency and structure means that the relations in assemblages cut across a material/cultural dualism (Barad, 1997, p. 180), and consequently, across micro, meso and macro levels of analysis (Taylor \& Ivinson, 2013, p. 668). There is nothing to prevent a relation conventionally thought of as 'micro' (e.g. a consumer transaction) and a 'macro' relation (e.g. a nation-state) to be drawn into assemblage by an affective flow; consequently, an assemblage may contain disparate elements from these different levels. For instance, Fox and Ward's (2008a) study of the pharmaceuticalisation of erectile dysfunction suggested an assemblage that incorporated the sexual performance of men and the financial performance of global pharmaceutical companies. Social inquiry must be open to the possibility that assemblages comprise elements from these different 'levels' or orders of magnitude, and that the affective flows between these elements are rhizomic rather than either 'top-down' or 'bottom-up'.

Fourth, this is a dynamic materiality, filled with affects, forces and desires, flows and intensities, assemblings and dis-aggregations, territorialisation and de-territorialisation, of becoming rather than being (Deleuze \& Guattari, 1988, p. 275). Though the 'macro-politics' of Deleuze and Guattari's work is exposed most floridly in their polemics against capitalism, psychoanalysis and familialism/Oedipus in AntiOedipus (Deleuze \& Guattari, 1984), and more broadly in antagonism to 'state' forms of science, art and philosophy (Deleuze \& Guattari, 1988, p. 109, 376), the foundation for this stance (and its utility in social inquiry) must be sought at a micropolitical level. Power resides in the affective flows between relations in 
assemblages, the aggregations and singularities these flows produce, and the capacities or constraints upon capacities produced in some - and not other - bodies, collectivities and non-human formations.

Clough (2004, p. 15) has suggested that the flows within assemblages are an 'affect economy' in which affective capacities switch bodies and other entities 'from one mode to another in terms of attention, arousal, interest, receptivity, stimulation, attentiveness, action, reaction, and inaction'. Deleuze and Guattari's (1984, p. 273) 'schizoanalytic' project may be understood as an effort to map the lines of becoming that flow through affect economies: the 'molar' aggregative lines, the 'molecular' singular lines that ascribe capacities, and the lines of flight that carry bodies into new possibilities. This schizoanalytic, rhizomic or 'nomadological' (Deleuze \& Guattari, 1988, pp. 22-23) enterprise supplies a methodology for social inquiry, a reminder that the study of bodies, assemblages and social formations is also the study of movements of desire, power, resistance and becoming other, and an encouragement to creative, rhizomic multiplicity and becoming in social theory and research (ibid., pp. 24-25). Concomitantly, as Renold and Ringrose (2008, p. 319) note, understanding resistance requires 'the persistent tracking of molecular flows and disruptions which signal moments of deterritorializations, becomings, and lines of flight'.

Finally, the materialist perspective raises questions about human capacities to produce research knowledge: the view that knowledge can be gleaned from observation of the world is itself founded in the anthropocentric privileging of human cognitive processes (Paden, 1987, p. 129). Conventionally, social inquiry (like other scientific inquiry) has been considered from the point of view of the researcher, who through efforts of reason, logic and scientific method, gradually imposes order upon 'data', and in so doing, 'makes sense' of the world. If, on the other hand, we see researcher and data (along with many other relations) as a 'research-assemblage' (Fox \& Alldred, 2013; Coleman \& Ringrose, 2013, p. 17; Masny, 2013, p. 340) with its own affect economy, we begin to recognise research as a territorialisation that shapes the knowledge it produces according to the particular flows of affect produced by its methodology and methods. This materialist analysis of research-asassemblage is pivotal to our understanding of research, and will form the basis for a critical framework for materialist social inquiry.

\section{The research-assemblage}

The idea of research as an assemblage derives from the DeleuzoGuattarian view of assemblages as 'machines' that link elements together affectively to do something, to produce something (Deleuze \& Guattari, 1988, p. 4). Applying the conception of a 'machinic assemblage' (Deleuze \& Guattari, 1988, p. 4), different stages in the research process such as data collection or analysis, or techniques used, for example, to sample data or increase validity, can be treated as a machine that works because of its affects. Thus, very generally, the affects in a 'data collection machine' apprehend aspects of an event, ${ }^{3}$ and act on these to produce an output called 'data'. An analysis machine processes this data according to rules of logic, deduction or inference to produce 'findings' in the form of generalities or summaries (Jackson \& Mazzei, 2013). A reporting machine takes these outputs of data analysis and creates knowledge products for dissemination: theory, policy and practice implications and so forth. In practice, as feminist critics have noted, research is often less linear (Ackerly \& True, 2010, p. 10): data collection and analysis may be used iteratively, 
or data may only 'make sense' when it is written up. But even in these more complex or even 'rhizomic' assemblages, what the constituent machines do can still be understood in terms of the affects that make them work.

So, a research methodology may be seen as a specific arrangement of machines, designed to shape how affect flows between its constituent relations, and what capacities these flows produce. The relations in a research-assemblage include the events to be researched, research tools such as questionnaires, interview schedules or other apparatus; recording and analysis technologies, computer software and hardware; theoretical frameworks and hypotheses; research literatures and findings from earlier studies; and, of course, researchers. To this are added contextual elements such as the physical spaces and establishments where research takes place; the frameworks, philosophies, cultures and traditions that surround scientific inquiry; ethical principles and ethics committees; and the paraphernalia of academic research outputs: libraries, journals, editors and reviewers, and readers. Precisely how event, instruments and researchers interact depends upon the intentional affective interactions defined by the machines used, in other words, the techniques and methodological strategies adopted. ${ }^{4}$ So, for example, a sampling frame determines which events are included in a study; the mathematical operators underpinning a summary statistic such as chi-squared transform these data into numbers; while a theoretical perspective brought to bear upon the research findings establishes specific capacities for how data are interpreted.

To understand more clearly the affect economy in the research-assemblage, consider an event $E$, such as Potts' (2004) study of Viagra use or the school dynamics described by Youdell and Armstrong (2011). From an assemblage perspective, $E$ is an assemblage with its own affect economy that makes it do whatever it does. When $E$ becomes the focus of a research study (which can be regarded as a further event and research-assemblage $R$ ), then the aim of this research-assemblage is to apply methods that can somehow identify the relations ('ABC') within the $E$ assemblage, explore the affects between these relations that make it work and assess from some contextual perspective the capacities that these affects produce. However, the researchassemblage $R$ comprises its own relations ('XYZ'), which are all the paraphernalia of academic inquiry: researcher, methodologies, research instruments, theories and so on. These relations have been assembled in order to engineer specific affective flows, with the objective of taking the event-assemblage $E$ or other similar events, and producing a textual or similar output that can be claimed as 'knowledge' of $E$.

If $R$ is to document, analyse and eventually textually report $E$, it must necessarily have the capacity to be affected by the relations ABC and the affects between them, in the sense that a research instrument or conceptual tool must be sufficiently sensitive to be useful as a means of inquiry. We may therefore regard the interaction between $E$ and $R$ as productive of a hybrid third assemblage $R / E$, with its own affective flow between A, B, C, X, Y and Z. ${ }^{5}$ This flow is distinct from those in either $E$ or $R$, but it is this hybridised affect economy that will produce the outputs of research such as the 'knowledge' of the $E$ assemblage, and potentially altered sensibilities concerning $E$ in the researcher, among research audiences, and perhaps also the people caught up in the event - sensibilities that a constructionist would describe as 'social constructions' of $E$.

We may conceive two extreme outcomes of this hybridisation between event and research affects. Where the XYZ relations in the research-assemblage have little affective capacity in their own right, then the $\mathrm{ABC}$ affects will territorialise $R / E$, 
generating research outputs that are anodyne or merely descriptive, theoretically uninformed, journalistic rather than critical. At the other extreme, if the XYZ affects within the research-assemblage are powerfully aggregative (e.g. by forcing data into categories, or using summary statistics or pre-determined analytical themes), then as the research seeks to analyse, apply theory, summarise, generalise and assert knowledge of $E$ in textual representation - they will radically re-territorialise the affective flow between $\mathrm{ABC}$ relations, to the extent that the 'knowledge' produced by $R / E$ no longer reflects the flow within $E$, distorting its representation in research outputs. Between these extremes lie a range of affective flows in $R / E$ assemblages with variable balances between $\mathrm{ABC}$ and $\mathrm{XYZ}$ affects, and these represent the majority of cases of social inquiry. In each and every research situation, there is a dynamic tension between the affective flows in $E$ and $R$ that has consequences for the knowledge and representations of the social world that research produces, for researchers, and potentially for the social world itself.

This materialist analysis allows us to look within the 'black box' of social inquiry and opens to scrutiny the micropolitics of different research-assemblages, of territorialisation and de-territorialisation, of who gains and who loses in the processes of research. The micropolitics of the research-assemblage is part of the broader materialist micropolitics that was discussed earlier, in the sense that power resides in the affective flows within the $R / E$ hybrid assemblages, territorialisations and de-territorialisations, aggregations, singularities and lines of flight that these flows produce, and the resultant capacities and constraints produced in bodies, collectivities and things. The micropolitics of the research-assemblage produce the social relations of modernist research.

Research epistemologies, designs, methods, techniques and tools may all be subjected to analysis of affective flows, to reveal the affect economies and micropolitics of social inquiry, discerning the aggregations and territorialisations that differing data collection, analysis and writing machines produce and the consequences for 'knowledge', for events and for researchers. Unlike 'spontaneous' assemblages in daily life, research-assemblages are machines designed to do specific tasks and comprise relatively few relations and affects. This makes them amenable to this kind of analysis, to assess how and why they work, and in what ways a change of methodology (for instance, from survey to ethnography) or of a data collection or analysis method alters the affective flow, and hence what kind of 'knowledge' they produce (Jackson \& Mazzei, 2013, p. 263).

For example, consider the affects involved in administering a questionnaire. These act on researcher and respondents, requiring a question to be asked, an answer to be supplied, this answer to be recorded and possibly allocated to a pre-coded category, and the instrument to be applied consecutively and independently to each respondent in turn, generating completed questionnaires ready to be fed into an analysis machine. Micropolitically, the machine acts as a filter on the affect economies of study events, extracting only certain data and categorising it according to the affect economy of the instrument rather than of the event itself. Similarly, thematic qualitative data analysis, in its simplest manifestation, is a machine that (manually or via software) organises and reduces non-numerical data, making it more manageable and amenable to systematic reporting. A pre-analysis code-generation affect first allocates a code to a range of similar textual occurrences, while a second aggregating affect takes each piece of data in turn and codes it according to this scheme, thus imposing an analyst-defined aggregation upon the disparate data from an event. 
Both these examples reveal aggregating affects that categorise or simplify eventassemblage affects, and this is a feature of many machines commonly used in social inquiry (e.g. a schedule that ensures all interview respondents are asked the same questions, or a 'grounded theory' analysis that privileges coherence and structure in data over divergence and randomness). Most research-assemblages and machines aim to produce simplicity where there was complexity, definition in place of indeterminacy, and evenness where there was variability, and tend to shift control of events studied firmly toward the researcher. This is perhaps unsurprising; after all research machines have been designed to enable researchers to do research; on the other hand, this analysis confirms arguments that research is in no sense a 'neutral' event. To limit the effect on the events it explores, research machines might replace aggregative with singular affects (for instance, a data analysis machine that counts but does not aggregate data from an event, or a case study that explores an event sui generis, on its own terms). Alternatively, aggregations within research-assemblages may be identified, and their effects thereby acknowledged and accounted for. We will return to this issue in the discussion.

This materialist analysis of research processes supplies a critical understanding of what social inquiry does, how affects in the research-assemblage interact with events and of the micropolitics of social inquiry. We shall now apply this insight into the research-assemblage, along with the principles of materialist social inquiry and a review of recent materialist studies, to assess what machines might be used to undertake materialist research.

\section{Assembling materialist social inquiry}

We reviewed 30 recent social science papers that gathered and/or analysed empirical data using a materialist ontology, and we will interrogate these in terms of the materialist ontology and insights into the research-assemblage set out earlier, looking first at designs, and then at the machines that collect, analyse and report data. This tripartite division is heuristic, and as will be seen, some of the papers we reviewed apply methods that are iterative, recursive or, as Deleuze and Guattari (1988, p. 8) would say, 'rhizomic', intertwining the stages of data gathering and analysis, or analysis and reporting. Such rhizomic machines can also be analysed in terms of their affect economies and micropolitics, and crucially, of what they do.

\section{Research design}

Materialist ontology suggests that in terms of design, a research-assemblage should:

- Attend not to individual bodies, subjects, experiences or sensations, but to assemblages of human and non-human, animate and inanimate, material and abstract, and the affective flows within these assemblages.

- Explore how affects draw the material and the cultural, and the 'micro', 'meso' and 'macro' into assembly together.

- Explore the movements of territorialisation and de-territorialisation, aggregation and disaggregation within the assemblages studied, and the consequent affect economies and micropolitics these movements reveal.

These propositions suggest that the objectives of materialist social inquiry are to reveal relations, affects and affect economies in assemblages, the capacities (and 
limits to capacities) produced in bodies, collectivities and social formations, and the micropolitics of these capacities and limits. Its orientation must be towards what things do, rather than what they 'are'; towards processes and flows rather than structures and stable forms; to matters of power and resistance; and to interactions that draw small and large relations into assemblage. A range of designs might fulfil some or all of those criteria, from ethnographic studies that explore the context in which events occur, through to surveys, which have the capacity to generate data at a population level on the incidence and prevalence of relations, affects and the capacities these produce, to methodologies such as Garfinkel's (1967) 'experiments with trust', in which participants tested the affects that territorialise daily life, and how small changes in interactions can de-territorialise affect economies and destabilise family assemblages.

However, all 30 studies we reviewed used qualitative designs, with ethnography the favoured methodology (Blaise, 2013; Dyke, 2013; Henriques, 2010; Holford, Renold, \& Huuki, 2013; Ringrose, 2011; Saldanha, 2002; Youdell \& Armstrong, 2011), sometimes with an auto-ethnographic element (Lambevski, 2005; McCormack, 2003; Whitaker, 2010). Others used exclusively in-depth qualitative interviewing (Cole, 2013; Masny \& Waterhouse, 2011; Mazzei, 2013; Potts, 2004), while some combined qualitative approaches (Fox \& Ward, 2008a; Ivinson \& Renold, 2013; Renold \& Ringrose, 2008, 2011; Ringrose, 2011).

The attraction of qualitative methodologies may lie in their capacity to contextualise events, thereby revealing the range of relations that comprise assemblages and affective economies. Observation and interviews can be used to identify assembled relations, and the affects and the capacities produced in bodies that together make an assemblage work. So, for example, Youdell and Armstrong (2011) described their school ethnography as a 'choreography' in which affects flow this way and that. They detailed the geographical and physical environment that contribute to the assemblages, as well as the interactions that mark out the affective flows, revealing what bodies can and cannot do, and the territorialisations and de-territorialisations that occur during the events they describe. Potts' (2004) study of Viagra demonstrated how qualitative interviewing could identify affects and body capacities within a 'Viagra-assemblage' comprising human and non-human relations. She revealed the territorialisations of male and female bodies that pharmaceutical therapy for erectile dysfunction produced, affecting the micropolitics of her respondents' sexualities and interactions with their partners.

Many of the authors in the review explicitly positioned their designs within the 'schizoanalytic' or 'rhizomic' DeleuzoGuattarian ontology (Deleuze \& Guattari, 1988 , p. 251) discussed earlier, to explore movements of territorialisation, de-territorialisation and 'lines of flight' in the settings they study (Cole, 2013, pp. 235-236; Masny, 2013, p. 346; Renold \& Ringrose, 2008, p. 320; St. Pierre, 1997, p. 186). In their study of horse/girl assemblages, Renold and Ivinson (2014) developed an innovative design that engaged with 'the thick and affective materiality' of young people's lives, using walking tours, photography, film-making and dance alongside ethnography and interviews, creating a rhizomic research-assemblage to explore the 'micro-intensities of everyday life'. For Masny (2013, p. 246), rhizoanalytic research is about creating 'lines of flight in which reality is immanent, rhizomatic, and unpredictable': the focus on affects, power and (de)territorialisation have the capacity to transform the enterprise of research, emphasising its transformative capacities, both 
for thinking events differently, and for all the bodies and other relations in the research-assemblage.

\section{Data collection}

Materialist data collecting machines must be able to:

- Identify assemblages of human and non-human, animate and inanimate, material and abstract, cutting across what are traditionally considered 'micro' and 'macro' levels.

- Explore how elements in assemblage affect and are affected, and assess what bodies and other things do: the capacities these affective flows produce.

- Identify territorialisations and de-territorialisations, and aggregating and singular flows within assemblages.

These imperatives radically change the focus of data collection away from 'humanistic' objectives of researching experience, beliefs and reflections found in anthropocentric research, while also eliding boundaries between the material and the cultural (matter and meaning) and the micro/macro scales of social production. Cutting across matter/meaning and micro/macro dualisms suggests collecting data from a variety of sources, and using a variety of methods. Our earlier proposition that a variety of qualitative and quantitative designs might be used in materialist research suggests a gamut of data collection methods from observation through to experimentation/quasi-experimentation, perhaps used as part of a mixed-methods approach, engineered to meet the objectives of identifying assemblages, affects (aggregating and singular) and capacities, while also encouraging reflexivity about how research is assembled.

This eclecticism was reflected in our review: Fox \& Ward (2008a) used interviews, online ethnography, media commentaries, official statistics and documentary sources as data to inform an analysis of pharmaceutical consumption, while Taguchi and Palmer (2013, p. 673) used their own affective responses and memories as data on events, alongside photographs, media reports, research papers, interviews and other resources to research school life, and St. Pierre (1997) argued for the inclusion of emotional, dream, and sensual data in social inquiry. Renold and Ivinson (2014) melded contemporary ethnography and interviews with historical data to generate a rhizomic on Welsh Valleys mining culture in their study of horse/girl assemblages, while these researchers also used a creative mix including photographs, films and walking tours alongside interview data (Ivinson \& Renold, 2013, p. 708). In Masny and Waterhouse (2011)'s study of literacy acquisition, data included drawings made by their respondents, and for Henriques (2010), sound and music were data in a study of Jamaican nightlife.

\section{Data analysis}

Materialist data analysis needs to:

- Take the assemblage as the primary focus for analysis, incorporating both nonhuman elements and human relations. 
- Explore affect economies and the territorialising and de-territorialising capacities produced in bodies, collectivities and other relations in assemblages.

- Examine how flows of affect within assemblages link matter and meaning, and 'micro' and 'macro' levels.

- Acknowledge the affective relations within the research-assemblage itself.

Materialist ontology shifts the focus of analysis from the ideas, actions and feelings of individualised subjects to the impersonal flows of affect through assemblages and the territorialisations of capacities these produce (Youdell \& Armstrong, 2011, p. 145). Human accounts can no longer be accorded validity on the basis of their 'authenticity', and methods such as interviews must be treated not as means to obtain subjective representations of the world but as evidence of how respondents are situated within assemblages (Juelskjaer, 2013, p. 759).

This shift in focus was reflected in the review. Studies by Fox and Ward (2006) and the present authors (Fox \& Alldred, 2013) applied a formalised approach to 'dredge' a range of data sources to provide a descriptive account of the relations and affects in assemblages, and the capacities that emerge from this assemblage. Ringrose (2011) sought to 'map how desire flows and power operates in the relationships between school and online assemblages and bodies' in her interview and online data, while Renold and Ivinson (2014) used 'transversal flashes' to reveal affective flows between historical and contemporary horse/girl assemblages. The diffractive (Haraway, 1997, p. 16) analysis used by Juelskjaer (2013) and Taguchi and Palmer (2013) to make sense of the 'timespacemattering' of events was an engaged and creative process that elided a strict distinction between data collection and analysis, and between 'researcher' and 'researched'.

The two of us would sit together in one of our studies, surrounded by all the data: the articles and books, written stories, photographs and images, or different web-sites on the internet on the screen in front of us. We read data out loud to each other or put the photographs into different software to highlight or downplay parts of them. We thus enacted agentic cuts in the construction of various encounters with data, while talking and telling each other stories or experiences, as a way to collaboratively produce knowing in this rhizomatic zigzagging flow. (Taguchi \& Palmer, 2013, p. 675)

Some studies in the sample applied an explicit DeleuzoGuattarian analysis (Deleuze \& Guattari, 1988, p. 367), focusing on territorialisations and de-territorialisations in the settings studied. Cole (2013, p. 224) applied nomadic analysis in his study of young Muslim Australians to address 'becoming, unstable identities, the questionable middle ground between participants and researchers, being lost and in-between research aims'. Renold and Ringrose (2011, p. 394) explored the schizoid dynamics of girls' subjectivities: territorialisation and de-territorialisation, aggregative (molar) and singular (molecular) flows and intensities. In a study of a library reading club, Alvermann's (2000, p. 119) analysis sought out 'discontinuities and ruptures' rather than linkages or networks.

\section{Reporting research}

Conventionally, what a research-reporting machine does is present the outputs produced by the data collection and analysis machines to an audience. However, the earlier discussion of research-assemblage micropolitics problematises this assessment, regarding any report of research as the product of a hybrid assemblage with 
an affect economy deriving from both the event and the machines of social inquiry. As already noted, social inquiry can territorialise and aggregate events in all sorts of ways, not least in the highly ritualised conventions of academic research writing and publishing that transform multi-register event-assemblages into the unidimensional medium of written text. Some scholars in the review challenged the latter territorialisation, connecting readers to events by including photographs (Ringrose \& Renold, 2012) or drawings (Masny \& Waterhouse, 2011). Whitaker's (2010, p. 127) described a rhizomic engagement that melded academic outputs with art installations, ecology and therapeutic activities, while a group of materialist scholars associated with Cardiff University have been collaborating with painters, sculptors and choreographers to explore multi-sensory research presentations (Renold \& Ivinson, 2014). ${ }^{6}$ Such initiatives alter the flow of affects in the research-assemblage between event, researcher and reader, and re-engage observed and observer (Taguchi \& Palmer, 2013, p. 674).

The materialist analysis of the research-assemblage presented earlier suggests a second, complementary approach. Whereas social constructionists rejected research claims to objectivity (Spears, 1997, p. 8), arguing that research accounts were themselves constitutive of the events they described (Kitzinger, 1987; Rose, 1998), the materialist assessment is less pessimistic. While recognising that research territorialises events in all sorts of ways, it also concluded that research machines can potentially be engineered to limit territorialisation and aggregation, revealing more or less of the event's affective economy. How research is reported offers a means to do this, mindfully redressing the territorialisations and aggregations of other machines in the research-assemblage by contextualising findings, re-privileging the affective flows of the event-assemblage, fostering affective flows between event and research audiences (Masny, 2013, p. 346) and finding ways to enable lines of flight that 'produce genuinely new ways of being in the world' (Renold \& Ivinson, 2014). Research reporting in this conception is reflexive, recursive and rhizomic, offering deterritorialisations and lines of flight to event assemblages and affects, and drawing research audiences into the research-assemblage, to contribute their own affects and capacities to its affective economy and micropolitics.

\section{Discussion}

The assessment of materialist social inquiry in the previous section has suggested an eclectic and pragmatic approach to research design and methods. While this assessment was firmly rooted in both the empirical data from a review of materialist studies and the concepts underpinning new materialism, our interrogation of the research-assemblage has been central to the analysis. This supplied understanding of what goes on when a research-assemblage interacts with an event-assemblage, and of the hybridised relations, affects and micropolitics that this interaction produces. Micropolitical analysis revealed both the processes of territorialisation and aggregation that underpin social inquiry's 'will to mastery' (White, 1991) and the possibility that these can be constrained, reversed or mitigated, producing knowledge of events for academic, policy or practical application.

We consider this focus on the micropolitics of research-assemblages as perhaps the principal contribution this paper makes to the project of materialist social inquiry. It discloses the affective flows between the many elements involved in research, the territorialisations and aggregations of events, researchers and audiences 
that occur as research-assemblages hybridise with event-assemblages and how research machines progressively turn an event into 'knowledge' or policy. This materialist analysis supplies a more nuanced view of the micropolitics between event, research process and researcher than constructionist epistemologies, which have tended to view research as constitutive of the objects it describes. Up to a point, our analysis would assent to this latter assessment: an aggregating and territorialising research-assemblage will dominate the affective flow in a hybrid $R / E$ assemblage, remaking the event-assemblage in its own image. But according to our analysis, the affects of an event also contribute to the hybrid research-assemblage, and (apart from intentionally fraudulent or fictitious research reports, or where the machines in a research-assemblage are wildly inappropriate, invalid or unreliable): aspects of the event's affective flow will remain within research outputs. ${ }^{7}$ Pulling apart a research-assemblage can specify and evaluate precisely what aggregations and territorialisations a research-assemblage has wrought as it has translated an event into research 'knowledge' or policy.

This can be taken further. Unpacking the affective flows in a research-assemblage both reveals its micropolitics, and provides the means to re-engineer a research-assemblage or research machine to manipulate its affect economy and thereby its micropolitics. For example, a research-assemblage (and its constituent data collection machine, validity machine, analysis machine and so forth) may be engineered to reduce an affect (for instance, an aggregation of data by pre-coding), and to foster others (e.g. a line of flight that offers a new perspective on an event), and we have described the schizoanalytic, rhizomic and diffractive methods used by studies in the review to achieve this. Second, aggregations can be acknowledged and their effects on the research process critically assessed and evaluated. Third, strategic de-territorialisations or disaggregations can be used to counter aggregations elsewhere in the research process, for instance, using a mix of methods, or as we have suggested, when research findings are reported or otherwise presented.

The analytical capacity to intervene in the micropolitics of research, we would suggest in conclusion, supplies materialist social inquiry with opportunities to shape the relationship between researchers, events, the tools of inquiry and audiences. We have shown in this paper how materialist ontology can be applied to interrogate the affect economies and micropolitics in research-assemblages themselves, and to provide a framework for designing and implementing materialist social inquiry. This micropolitical approach enables designs and methods to be engineered from the bottom up, and as interest in materialist approaches to social inquiry increases, offers a strategy for developing methodologies - both to understand the world, and to change it.

\section{Notes}

1. This melds Deleuze's Spinozism, most succinctly set out in Spinoza: Practical Philosophy (Deleuze, 1988) and Guattari's development of schizoanalytic theory, for which, see Guattari (1995a, 1995b). For a critical review of the ontological positions underpinning DeleuzoGuattarian ontology, see Fox \& Alldred (2013).

2. As part of an effort to increase accessibility to materialist theory, we use the terms 'aggregative' and 'singular' in place of Deleuze and Guattari's (1984, p. 286) 'molar' and 'molecular': terms derived from physical chemistry.

3. We use the term 'event' to connote any social/spatiotemporal occurrence that can be an object of inquiry. 
4. Other 'extraneous' affects (for instance, a researcher's 'bias' or fraudulence, or the prejudices of the scientific community) will also influence the research-assemblage.

5. This hybridisation model could also be applied to any observation of an event, whether by a 'lay' observer, a journalist, a poet or a professional comedian. What differentiates social inquiry is that the machines and thus affective economies are more formalised and underpinned by social science epistemological propositions.

6. The use of innovative creative approaches was the subject of a 2010 ESRC seminar series 'Researching Affect in the Social Sciences': http://vimeo.com/channels/affectresearch.

7. At the same time - unlike realist analysis, materialist social inquiry's flat, relational ontology de-essentialises events, taking an assemblage's emergent capacities, fluxes and becomings as its objects of study.

\section{Notes on contributors}

Nick J. Fox is an honorary professor of Sociology at the University of Sheffield School of Health and Related Research.

Pam Alldred is a senior lecturer and director of the Centre for Youth Work Studies in the Division of Social Work, Brunel University.

\section{References}

Ackerly, B., \& True, J. (2010). Doing feminist research in political and social science. London: Palgrave Macmillan.

Alvermann, D. E. (2000). Research libraries, literacies, and lives: A rhizoanalysis. In E. St. Pierre \& W. S. Pillow (Eds.), Working ruins: Feminist poststructural theory and methods in education (pp. 114-128). London: Routledge.

Anderson, B. (2010). Becoming and being hopeful: Towards a theory of affect. Environment and Planning D: Society and Space, 24, 733-752.

Ansell Pearson, K. (1999). Germinal life. London: Routledge.

Barad, K. (1997). Meeting the universe halfway; realism and social constructivism without contradiction. In L. H. Nelson \& J. Nelson (Eds.), Feminism, Science and the Philosophy of Science (pp. 161-194). Dordrecht: Kluwer Academic.

Berger, P., \& Luckmann, T. (1971). The social construction of reality. Harmondsworth: Penguin University Books.

Blaise, M. (2013). Activating micropolitical practices in the early years: (Re)assembling bodies and participant observations. In R. Coleman \& J. Ringrose (Eds.), Deleuze and research methodologies (pp. 184-200). Edinburgh: Edinburgh University Press.

Braidotti, R. (2000). Teratologies. In I. Buchanan \& C. Colebrook (Eds.), Deleuze and feminist theory (pp. 156-172). Edinburgh: Edinburgh University Press.

Braidotti, R. (2006). Transpositions. Cambridge: Polity Press.

Braidotti, R. (2013). The Posthuman. Cambridge: Polity Press.

Buchanan, I. (2008). Power, theory and praxis. In I. Buchanan \& N. Thoburn (Eds.), Deleuze and politics (pp. 13-34). Edinburgh: Edinburgh University Press.

Clough, P. T. (2003). Affect and control: Rethinking the body 'beyond sex and gender'. Feminist Theory, 4, 359-364.

Clough, P. T. (2004). Future matters: Technoscience, global politics, and cultural criticism. Social Text, 22(3), 1-23.

Clough, P. T. (2008). The affective turn: Political economy, biomedia and bodies. Theory, Culture \& Society, 25, 1-22.

Cole, D. R. (2013). Lost in data space: Using nomadic analysis to perform social science. In R. Coleman \& J. Ringrose (Eds.), Deleuze and research methodologies (pp. 219-237). Edinburgh: Edinburgh University Press.

Coleman, R., \& Ringrose, J. (2013). Introduction. In R. Coleman \& J. Ringrose (Eds.), Deleuze and research methodologies (pp. 1-22). Edinburgh: Edinburgh University Press.

Conley, V. A. (1990). Becoming-woman now. In I. Buchanan \& C. Colebrook (Eds.), Deleuze and feminist theory (pp. 18-37). Edinburgh: Edinburgh University Press. 
Coole, D. H., \& Frost, S. (2010). New materialisms: Ontology, agency, and politics. Durham, NC: Duke University Press.

DeLanda, M. (2006). A new philosophy of society. London: Continuum.

Deleuze, G. (1988). Spinoza: Practical philosophy. San Francisco, CA: City Lights.

Deleuze, G., \& Guattari, F. (1984). Anti-Oedipus: Capitalism and schizophrenia. London: Athlone.

Deleuze, G., \& Guattari, F. (1988). A thousand plateaus. London: Athlone.

Dyke, S. (2013). Disrupting anorexia nervosa: An ethnography of the Deleuzian event. In R. Coleman \& J. Ringrose (Eds.), Deleuze and research methodologies (pp. 145-163). Edinburgh: Edinburgh University Press.

Fox, N. J., \& Alldred, P. (2013). The sexuality-assemblage: Desire, affect, anti-humanism. Sociological Review, 61, 769-789.

Fox, N. J., \& Ward, K. J. (2006). Health identities: from expert patient to resisting consumer. Health, 10, 461-479.

Fox, N. J., \& Ward, K. J. (2008a). Pharma in the bedroom ... and the kitchen. The pharmaceuticalisation of daily life. Sociology of Health and Illness, 30, 856-868.

Fox, N. J., \& Ward, K. J. (2008b). What are health identities and how may we study them? Sociology of Health and Illness, 30, 1007-1021.

Garfinkel, H. (1967). Studies in ethnomethodology. Englewood Cliffs, NJ: Prentice Hall.

Giddens, A. (1981). A contemporary critique of historical materialism. London: Macmillan.

Giddens, A. (1987). Social theory and modern sociology. Cambridge: Polity Press.

Grosz, E. (1994). Volatile bodies. Bloomington, IN: Indiana University Press.

Guattari, F. (1995a). Chaosmosis. Sydney: Power Publications.

Guattari, F. (1995b). Chaosophy. New York, NY: Semiotexte.

Haraway, D. (1997). Modest Witness @ Second Millennium.Femaleman meets Oncomouse. New York, NY: Routledge.

Henriques, J. F. (2010). The vibrations of affect and their propagation on night out on Kingston's dancehall scene. Body \& Society, 16, 57-89.

Holford, N., Renold, E., \& Huuki, T. (2013). What (else) can a kiss do? Theorizing the power plays in young children's sexual cultures. Sexualities, 16, 710-729.

Ivinson, G., \& Renold, E. (2013). Valleys' girls: Re-theorising bodies and agency in a semirural post-industrial locale. Gender and Education, 25, 704-721.

Jackson, A. Y., \& Mazzei, L. A. (2013). Plugging one text into another: Thinking with theory in qualitative research. Qualitative Inquiry, 19, 261-271.

Juelskjaer, M. (2013). Gendered subjectivities of spacetimematter. Gender and Education, $25,754-768$.

Kitzinger, C. (1987). The social construction of lesbianism. London: Sage.

Lambevski, S. A. (2005). Bodies, schizo vibes and hallucinatory desires - Sexualities in movement. Sexualities, 8, 570-586.

Latour, B. (2005). Reassembling the social. Oxford: Oxford University Press.

Levi-Strauss, C. (1986). The raw and the cooked. Harmondsworth: Penguin.

Masny, D. (2013). Rhizoanalytic pathways in qualitative research. Qualitative Inquiry, 19, $339-348$.

Masny, D., \& Waterhouse, M. (2011). Mapping territories and creating nomadic pathways with multiple literacies theory. Journal of Curriculum Theorizing, 27, 287-307.

Massumi, B. (1988). Translator's foreword and notes. In G. Deleuze \& F. Guattari (Eds.), $A$ thousand plateaus (pp. ix-xix). London: Athlone.

Massumi, B. (1996). The autonomy of affect. In P. Patton (Ed.), Deleuze: A critical reader (pp. 217-239). Oxford: Blackwell.

Mazzei, L. A. (2013). Desire undone: Productions of privilege, power and voice. In R. Coleman \& J. Ringrose (Eds.), Deleuze and research methodologies (pp. 96-110). Edinburgh: Edinburgh University Press.

McCormack, D. (2003). An event of geographical ethics in spaces of affect. Transactions of the Institute of British Geographers, 28, 488-507.

Mulcahy, D. (2012). Affective assemblages: Body matters in the pedagogic practices of contemporary school classrooms. Pedagogy, Culture \& Society, 20, 9-27.

Paden, R. (1987). Foucault's anti-humanism. Human Studies, 10, 123-141. 
Potts, A. (2004). Deleuze on Viagra (or, what can a Viagra-body do?). Body \& Society, 10, $17-36$.

Renold, E., \& Ivinson, G. (2014). Horse-girl assemblages: Towards a posthuman cartography of girls' desires in an ex-mining valleys community. Retrieved from https://www.acade mia.edu/4957827

Renold, E., \& Mellor, D. (2013). Deleuze and Guattari in the nursery. In R. Coleman \& J. Ringrose (Eds.), Deleuze and research methodologies (pp. 23-41). Edinburgh: Edinburgh University Press.

Renold, E., \& Ringrose, J. (2008). Regulation and rupture: Mapping tween and teenage girls' resistance to the heterosexual matrix. Feminist Theory, 9, 313-338.

Renold, E., \& Ringrose, J. (2011). Schizoid subjectivities? Re-theorizing teen girls' sexual cultures in an era of 'sexualization'. Journal of Sociology, 47, 389-409.

Ringrose, J. (2011). Beyond discourse? Using Deleuze and Guattari's schizoanalysis to explore affective assemblages, heterosexually striated space, and lines of flight online and at school. Educational Philosophy and Theory, 43, 598-618.

Ringrose, J., \& Renold, E. (2012). Slut-shaming, girl power and 'sexualisation': Thinking through the politics of the international SlutWalks with teen girls. Gender and Education, 24, 333-343.

Rose, N. (1998). Inventing our selves. Psychology, power and personhood. Cambridge: Cambridge University Press.

Saldanha, A. (2002). Music tourism and factions of bodies in Goa. Tourist Studies, 2, 43-62.

Spears, R. (1997). Introduction. In T. Ibanez \& L. Iniguez (Eds.), Critical social psychology (pp. 1-26). London: Sage.

St. Pierre, E. A. (1997). Methodology in the fold and the irruption of transgressive data. International Journal of Qualitative Studies in Education, 10, 175-189.

Taguchi, H. L., \& Palmer, A. (2013). A more 'livable' school? A diffractive analysis of the performative enactments of girls' ill-/well-being with(in) school environments. Gender and Education, 25, 671-687.

Tamboukou, M. (2003). Interrogating the emotional turn: Making connections with Foucault and Deleuze. European Journal of Psychotherapy Counselling and Health, 6, 209-223.

Taylor, C. A., \& Ivinson, G. (2013). Material feminisms: New directions for education. Gender and Education, 25, 665-670.

Thacker, E. (2005). Biophilosophy for the 21st century. Ctheory.net. Retrieved from http:// www.ctheory.net/articles.aspx?id $=472$

Thrift, N. (2004). Intensities of feeling: Towards a spatial politics of affect. Geografiska Annaler, Series B: Human Geography, 86, 57-78.

van der Tuin, I., \& Dolphijn, R. (2010). The transversality of new materialism. Women: $A$ Cultural Review, 21, 153-171.

Whitaker, P. (2010). Groundswell: The nature and landscape of art therapy. In C. H. Moon (Ed.), Materials and media in art therapy (pp. 119-136). London: Routledge.

White, S. (1991). Political theory and postmodernism. Cambridge: Cambridge University Press.

Youdell, D., \& Armstrong, F. (2011). A politics beyond subjects: The affective choreographies and smooth spaces of schooling. Emotion, Space and Society, 4, 144-150. 